\title{
EDITORIAL
}

\section{Idiopathic aortitis: an underrecognized vasculitis}

\author{
Nicolò Pipitone and Carlo Salvarani* \\ See related research by Schmidt et al., http://arthritis-research.com/content/13/3/R87
}

\begin{abstract}
Aortitis is a general term denoting inflammation of the aortic wall. Various infectious and non-infectious diseases can be complicated by aortitis; in addition, isolated idiopathic aortitis has also been described. In a 12-year nationwide Danish population-based study, the prevalence of aortitis among 1,210 resected thoracic aorta samples was $6.1 \%$, with nearly three-quarters of cases being idiopathic. Identified risk factors for aortitis included advanced age, a history of connective tissue disease, diabetes mellitus, and heart valve pathology. As in virtually all pathological studies, this study has a bias toward reporting the most severe cases of aortitis requiring surgical repair.
\end{abstract}

Aortitis is a general term for a spectrum of disorders characterized by inflammation of the aortic wall. A variety of infectious and non-infectious diseases can be complicated by aortitis; in addition, isolated idiopathic aortitis - usually involving the thoracic aorta - has also been described.

In the previous issue of Arthritis Research \& Therapy, Schmidt and colleagues report on the prevalence and predictors of biopsy-proven aortitis in a 12-year nationwide Danish population-based study [1]. Aortic aneurysms and dissections were the most common (76.2\%) indications for surgery. The prevalence of aortitis among 1,210 resected thoracic aorta samples was $6.1 \%$, with nearly three-quarters of cases being idiopathic and one-quarter being associated with diseases known to cause aortitis. Only $14 \%$ of aortitis cases were linked to giant cell arteritis (GCA), and none to Takayasu arteritis (TA). Identified risk factors for aortitis included advanced age, a history of connective tissue disease, diabetes mellitus, and heart valve pathology.

*Correspondence: Salvarani.carlo@asmn.re.it

Department of Rheumatology, Arcispedale Santa Maria Nuova, Viale Risorgimento 80, 42100 Reggio Emilia, Italy
This study is unique in being population-based. Nevertheless, the prevalence of idiopathic aortitis found is remarkably similar to that reported by similar studies from surgical centers, in which idiopathic aortitis made up 4.3 to $8.4 \%$ of all aortitis cases [2-4]. Such a close concordance comes as no surprise, because the indications for surgery mentioned in Schmidt and colleagues' study [1] largely overlap with those from other centers [2-4]. A common bias to this study and previous studies from surgical centers is a skew towards reporting aortitis cases complicated by aortic aneurysms and, to a lesser extent, dissections requiring surgical repair. This bias implies that aortitis characterized by asymptomatic vessel wall thickening, lumen stenosis, or small aneurysms is likely to have been underestimated. Stated otherwise, idiopathic aortitis may be both more common and less severe than it would appear from the results of this study.

Systemic disorders known to be complicated by aortitis were identified in one-quarter of patients in this study [1], and in a quite wide range (5 to $49 \%$ ) of previously reported patients [4-6]. Such discrepancies may be ascribed to the use of different criteria for disease classification as well as to diverse local ascertainment practices. Histologically, idiopathic aortitis is virtually indistinguishable from GCA and TA [3], while GCA and TA can be both associated with aortitis and with aneurysm formation $[7,8]$. Idiopathic aortitis may thus lie at the one end of a disease spectrum encompassing both TA and GCA.

A related issue is whether other large vessels may be involved in patients with aortitis. In this regard, a review of 64 patients with (mostly idiopathic) aortitis undergoing ascending aortic aneurysm resection found additional vascular imaging abnormalities in $72 \%$ of cases [3] while another study described manifestations of systemic arterial disease in $64 \%$ of 45 patients with non-infectious aortitis, one-half of whom had idiopathic aortitis [5]. Therefore, it is plausible that a proportion of aortitis patients might have vasculitis affecting other vessels in addition to the aorta, although in some patients arterial changes might be due to atherosclerosis and hypertension.

Advanced age, a history of connective tissue disease, diabetes mellitus, and heart valve pathology were identified in the study by Schmidt and colleagues as risk factors 
for the development of aortitis [1]. Older age is a recognized risk factor for GCA as well as a predictor of idiopathic aortitis according to other reports [2-4], although the mechanisms by which older age predisposes to vasculitis remain debated. Connective tissue disease has also been implicated in the pathogenesis of vasculitis in other studies [2,4]. Diabetes mellitus was found to be associated with aortitis [1], contrary to the findings of a previous study [9]. Because of the small number of cases and controls with diabetes, the wide confidence intervals, and the borderline significance, however, a type I error cannot be ruled out [1]. On the other hand, the study by Schmidt and colleagues [1] did not confirm previously described associations of aortitis with smoking [9] and with hypertension [10]. These discrepancies may be due to different definitions of risk factors, ascertainment methods, and perhaps complex interactions between predisposing and protecting factors, including genetic background and treatments. Analysis based on dichotomous variables may also be an oversimplistic way of assessing the impact of risk factors because it may not adequately take into account the duration of exposure to, and the severity of, risk factors. Finally, one should also bear in mind that some of the associations described may be related, at least in part, to aneurysm formation rather than to vasculitis per se. With these caveats in mind, the study by Schmidt and colleagues is an important contribution to a poorly recognized disorder [1]. Clinical and imaging studies may help to address some of the issues left unresolved by this study.

\section{Abbreviations}

GCA, giant cell arteritis; TA, Takayasu arteritis.
Competing interests

The authors declare that they have no competing interests.

Published: 22 July 2011

References

1. Schmidt J, Sunesen K, Kornum JB, Duhaut P, Thomsen RW: Predictors for pathologically confirmed aortitis after resection of the ascending aorta: a 12-year Danish nationwide population-based cross-sectional study. Arthritis Res Ther 2011, 13:R87.

2. Pacini D, Leone O, Turci S, Camurri N, Giunchi F, Martinelli GN, Di Bartolomeo $R$ : Incidence, etiology, histologic findings, and course of thoracic inflammatory aortopathies. Ann Thorac Surg 2008, 86:1518-1523.

3. Liang KP, Chowdhary VR, Michet CJ, Miller DV, Sundt TM, Connolly HM, Crowson CS, Matteson EL, Warrington KJ: Noninfectious ascending aortitis: a case series of 64 patients. J Rheumatol 2009, 36:2290-2297.

4. Rojo-Leyva F, Ratliff NB, Cosgrove DM, III, Hoffman GS: Study of 52 patients with idiopathic aortitis from a cohort of 1,204 surgical cases. Arthritis Rheum 2000, 43:901-907.

5. Miller DV, Isotalo PA, Weyand CM, Edwards WD, Aubry MC, Tazelaar HD: Surgical pathology of noninfectious ascending aortitis: a study of 45 cases with emphasis on an isolated variant. Am J Surg Pathol 2006, 30:1150-1158.

6. Merkel PA: Noninfectious ascending aortitis: staying ahead of the curve. J Rheumatol 2009, 36:2137-2140.

7. Evans JM, O'Fallon WM, Hunder GG: Increased incidence of aortic aneurysm and dissection in giant cell (temporal) arteritis. A population-based study. Ann Intern Med 1995, 122:502-507.

8. Vanoli M, Daina E, Salvarani C, Sabbadini MG, Rossi C, Bacchiani G, Schieppati A, Baldissera E, Bertolini G; Itaka Study Group: Takayasu's arteritis: a study of 104 Italian patients. Arthritis Rheum 2005, 53:100-107.

9. Chowdhary VR, Crowson CS, Liang KP, Michet CJ Jr, Miller DV, Warrington KJ, Matteson EL: Cardiovascular risk factors and acute-phase response in idiopathic ascending aortitis: a case control study. Arthritis Res Ther 2009, 11:R29.

10. Ito S, Akutsu K, Tamori Y, Sakamoto S, Yoshimuta T, Hashimoto H, Takeshita S: Differences in atherosclerotic profiles between patients with thoracic and abdominal aortic aneurysms. Am J Cardiol 2008, 101:696-699.

doi:10.1186/ar3389

Cite this article as: Pipitone N, Salvarani C: Idiopathic aortitis: an underrecognized vasculitis. Arthritis Research \& Therapy 2011, 13:1 19. 